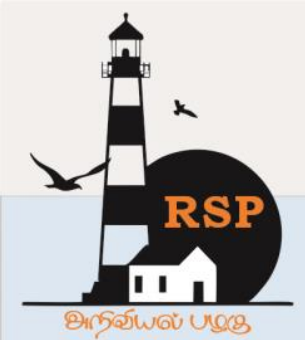

INTERNATIONAL RESEARCH JOURNAL ON ADVANCED SCIENCE HUB

\title{
An Enhancement of Properties on Al7075 and Al6061 Dissimilar Materials Welded by TIG Process
}

S.Santhosh Kumar ${ }^{1}$, G. Godwin',

${ }^{1}$ Head and Lecturer, Department of Mechanical Engineering ST.Joseph University In Tanzania Dar Es Salaam.

${ }^{2}$ Asst.Professor, Department of Mechanical Engineering, Satyam College of Engineering and Technology, Kanyakumari, India.

\section{Abstract}

Aluminium alloy was a predominant metal among alloys elements. The aluminum alloys like Al7075 and Al6061 which has the major elements of $\mathrm{Zn}, \mathrm{Mg}, \mathrm{Cu}$, Si with which it will improve the hard-brittle crystalline structure and conductivity. To enhance the properties of dissimilar joint metal, TIG (Tungsten Inert Gas) welding is propagated. Mechanical properties like Tensile, Impact, Bending, micro-hardness and the study about microstructure analysis were carried out. As a result, the energy absorbed by the dissimilar joint metal is $16 \mathrm{~J}$ and the hardness of dissimilar joint metal is $51.3 \mathrm{HV}$.It revealed that, there is a high impact strength and micro-hardness properties. Consequently, the microstructure (HAZ) image exhibits good bonding strength and sufficient plastic deformation was improved due to fine distribution of grains.

\section{Keywords: Tungsten Inert Gas Welding, HAZ, Tensile, Bending, Impact, Micro-hardness}

\section{Introduction}

To produce a high quality welding Tungsten Inert Gas (TIG) welding was suggested by many researchers. It can also help to achieve faster welding speed, less distortion and even thin welding sheets can be easily welded with less skill required $[1,2]$. However to perform precise and uniform welding some important parameters like welding speed, welding current, welding voltage, electrode diameter and gap, work piece material, shielding gas were considered. Depending upon the type of material selection of parameters was profiled along the basis of the specifications of welding machine used. By proper welding and different welding parameters welding defects can be controlled. A comparative outcome between TIG welding and base material can be investigated using Tensile, Impact test and investigation of Microstructure at different zones of the weldment [3]. Furthermore, it was observed that a failure at welded zone over the welded specimen after conducting tensile test. A metallographic view shows the revealed grain structure at the welded zone to improve the mechanical properties [4]. The UTS is usually found by performing a tensile test and recording the stress versus strain, the highest point of the stress-strain curve is the UTS. It is an intensive property; therefore its value does not depend on the size of the test specimen. However, it is dependent on other factors, such as the preparation of the specimen, the presence or otherwise of surface defects, and the temperature of the test environment and the material $[5,6]$. The use of $\mathrm{Al}$ filler also improves mechanical properties and has lower ductility. Consequently, the stress- strain curves exhibits lower plasticity but the joint with the maximum UTS had elongation and higher plasticity than the joint with the minimum UTS. The increased grain size form 
re-crystallized microstructures of the partially melted zone (PMZ) of the A7075-T651 alloy were equiaxed. The HAZ was not distinguishable or might have existed along with PMZ. The melting of base material during the welding process will change the microstructure and the mechanical properties.[7, 13] Throughout, of Base Metal was distributed by an irregular distribution of coarse particles and due to increase in heat input the width of HAZ (Heat Affected Zone) increases from 335 to $690 \mu \mathrm{m}$.[8] A limited elongation capability for as-welded joint was due to the fact that during testing was concentrated more in the HAZ, which is the weakest part of the specimen[9, $10,11]$.Thereby, reducing the strength of the welded joint by the formation of coarse grains in HAZ was observed in the specimens of $70 \mathrm{~A}$ and $80 \mathrm{~A}[12,13,14]$. In addition, the weld area is heated and fusion occurs during the period of pulse current states that the higher current level and the impulse frequency was between $0.5 \mathrm{~Hz}$ and 6 HZ.[15,16] By applying pulse welding a better depth of penetration and fusion of filler material with parent metal is obtained and by this it improves strength and ductility of weldments [17, 18]. A limited literature is available, in current design standards which provide suitable residual factors for the post-fire mechanical properties of Aluminium alloys.[19] Maximum strength was suitable at bevel angles between $30^{\circ}$ to $45^{\circ}$ [20].

Table.1.Chemical composition of Al 6061 and Al 7075

\begin{tabular}{|l|l|l|l|l|l|l|l|l|l|}
\hline $\begin{array}{l}\text { Compositi } \\
\text { on }\end{array}$ & $\mathbf{M g}$ & $\mathbf{S i}$ & $\mathbf{F e}$ & $\mathbf{C u}$ & $\mathbf{C r}$ & $\mathbf{M n}$ & $\mathbf{Z n}$ & $\mathbf{T i}$ & Al \\
\hline $\begin{array}{l}\text { Wt \% of } \\
\text { Al6061 }\end{array}$ & 0.63 & 0.42 & 0.42 & 0.12 & .19 & 0.05 & 0.02 & 0.08 & Bal. \\
\hline $\begin{array}{l}\text { Wt \% of } \\
\text { Al7075 }\end{array}$ & $\begin{array}{l}2.10- \\
2.90\end{array}$ & 0.40 & 0.50 & $\begin{array}{l}1.20- \\
2.00\end{array}$ & $\begin{array}{l}0.18- \\
0.28\end{array}$ & 0.30 & $\begin{array}{l}5.10- \\
6.10\end{array}$ & 0.20 & Bal. \\
\hline
\end{tabular}

The grain structure of the 7075 alloy was seen to be oriented in rolling direction of Aluminium sheet, a fine equiaxed dendritic network grains were observed in weld metal at the fusion zone [21]. Currently the nuggets in weld dissolution of strengthening precipitates in weld of $\mathrm{Al}$ alloy. The elongated grains in one direction have revealed interdendritic eutectic with light grey particles of FeAl3 present in the Al solid solution [22]. Both similar joint and parent joint a material has superior tensile strength than the dissimilar joint materials [23]. Excessive porosity formation and cracking was revealed in the dissimilar Al- alloy [24]. Good bonding and plastic deformation gave the fine equi-axed grains, good ductility due to the presence of manganese content which attributes high tensile strength. The coarse grain occurring condition of 7075 alloy is narrower than that of 6061 alloy. $\mathrm{Cr}$ or $\mathrm{Zr}$ addition could inhibit the grain coarsening even under the compression condition which resulted in the most possible coarse grain in the 7075 base alloy [25].

Table.2. Filler wire composition

\begin{tabular}{|c|c|c|c|c|c|c|c|}
\hline Material & $\mathbf{C u}$ & $\mathbf{S i}$ & $\mathbf{M n}$ & $\mathbf{M g}$ & $\mathbf{F e}$ & $\mathbf{C r}$ & $\mathbf{A l}$ \\
\hline $\begin{array}{c}\text { Wt \% of } \\
\text { Al4043 } \\
\text { filler wire }\end{array}$ & 0.17 & $\begin{array}{c}4.5- \\
6.0\end{array}$ & 0.24 & 0.05 & 0.05 & 0.05 & Bal. \\
\hline
\end{tabular}

\section{Experimental Setup}

A. Specimen Preparation

A material used for this study was7075 Aluminum alloy and 6061 Aluminium alloy, and its chemical composition is shown in Table 1. Test specimens were prepared in the dimension of
$200 \times 150 \times 12 \mathrm{~mm}$, using power hack saw and milling machine. Double Edge Chamfering was prepared using vertical milling machine with semi right angle $\left(45^{\circ}\right)$ in both directions shown in Fig. 1. For a high quality weld the rate of deposition was slow and it limits the range of application in terms of thickness was produced by Lincoln 
Electrical Precision TIG 375 GTAW machine, whereas A14043 filler wire is used join specimens the composition elements were shown in table. 2. Electrode holder is available in size that range from 150 to 500 Amps to weld dissimilar materials. The specification of efficiency, Arc voltage, A.C voltage, Current range was $0.6,20 \mathrm{~V}$ to $80 \mathrm{~V}, 30 \mathrm{~V}$ to $80 \mathrm{~V}, 125 \mathrm{~A}$ to $600 \mathrm{~A}$ respectively.

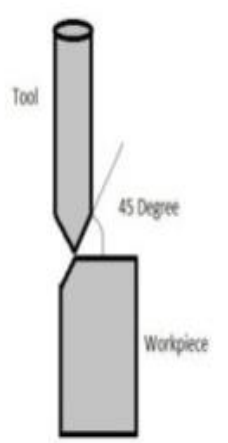

Fig.1. Edge preparation

B. Mechanical Properties Test

After the welding, the welded plates are cut into ASTM standard for tensile, impact, bending and micro hardness test by using CNC cutting machine. Tensile test was done on computerized INSTRON Universal testing machine. The gauge thickness and length of tensile test according to ASTM E8 standard load applied about $400 \mathrm{KN}$. The material to be tested, also known as a specimen, is machined to standardized dimensions. A typical specimen has a diameter of $12.5 \mathrm{~mm}$ and a gauge length of $50 \mathrm{~mm}$. The crystal structures are collapsed in various load condition, in this case applied load range is randomly applied upto 1-2 Kgf . The specimens were prepared as per ASTM standard E407 metallographic procedure. Modified Keller reagent and Wecks reagent were used to reveal the microstructure. The material flow, grain size and grain orientations were carried out using an optical microscope.

\section{Results and Discussion}

\section{A. Tensile Test}

From the values of UTS obtained for Al7075-Al6061, it is observed that dissimilar weldment shown in Fig. 2 (a) depicted maximum ultimate tensile strength when compared to similar weldment materials. But, there was a significant change in the value of percentage in elongation $4.68 \%$ which is shown in table 3 .

Table. 3 Tensile test result for dissimilar weld material

\begin{tabular}{|l|l|l|l|}
\hline $\begin{array}{l}\text { Details of } \\
\text { Sample }\end{array}$ & $\begin{array}{l}\text { Tensile } \\
\text { strength } \\
\text { (Mpa) }\end{array}$ & $\begin{array}{l}\text { Yield } \\
\text { strength } \\
\text { (Mpa) }\end{array}$ & $\begin{array}{l}\text { Elongation } \\
\text { (\%) }\end{array}$ \\
\hline $\begin{array}{l}\text { Al 7075 - } \\
\text { Al 6061 }\end{array}$ & 51.53 & 30.91 & 4.68 \\
\hline
\end{tabular}

Un-welded parent metal achieved about $537 \mathrm{MPa}$ and $570 \mathrm{MPa}$, with respect to the yield strength and the tensile strength for TIG welding. Consequently, $110 \mathrm{MPa}$ and $118 \mathrm{MPa}$ the yield and tensile strength of GMAW joint were observed [20]. The tensile strength of the dissimilar joint is lower the value is shown in Table 3. The yield strength and tensile strength of GMAW joints are $141 \mathrm{MPa}$ and $163 \mathrm{MPa}$, respectively. However, the yield strength and tensile strength of unwelded parent metal are $302 \mathrm{MPa}$ and $335 \mathrm{MPa}$, respectively. Similarly, the yield strength and tensile strength of GTAW joints are $188 \mathrm{MPa}$ and $211 \mathrm{MPa}$, respectively which are $37 \%$ lower compared to parent metal [25]. For, a lower tensile strength a brittle fracture and as well as higher ductility AA6061-T6 failure occurred [23]. Nevertheless, the bending properties were improved upto $3.82 \mathrm{KN}$, the tested material was shown in Fig.2 (b).

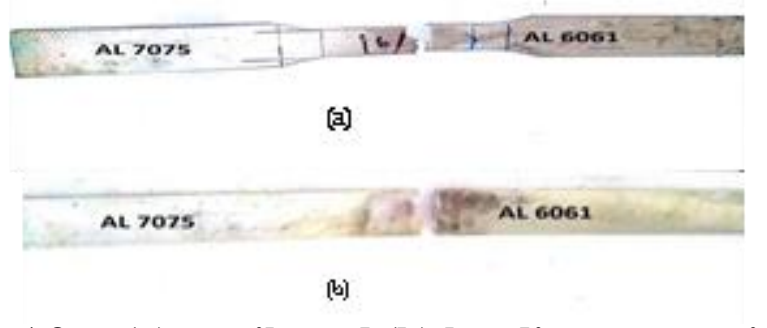

Fig.2.After (a) tensile and (b) bending test specimen 


\section{B. Impact test}

A weld can absorb only $4 \mathrm{~J}$ in GMAW and $6 \mathrm{~J}$ in GTAW as compared to $12 \mathrm{~J}$ absorbed by the base metal [23]. Table 4. shows the dissimilar material A17075-Al6061 TIG weld achieved 16J while impact.

\section{Energy absorbed Level for Aluminum weld.}

\begin{tabular}{|l|l|}
\hline Details of sample & Impact in joules \\
\hline Al7075-Al6061 & 16 \\
\hline
\end{tabular}

C. Microhardness Test

The resulting depth of impression was measured by the help of a microscope as shown in Fig. 3. Using hardened steel ball indenter of $10 \mathrm{~mm}$ diameter was fixed on the BHN machine demonstrated in the experimental set up. Under this condition, the literatures reported that the hardness of Al6061 alloy increased from $3875 \mathrm{HV}$ to $10475 \mathrm{HV}$, whereas, the 7075 alloy increased from $13575 \mathrm{HV}$ to $21075 \mathrm{HV}$. The micro hardness of similar and dissimilar RSW weld joints, the lowest hardness was on Al6661 base metal. Currently, the dissolution of strengthening precipitates in welds of $\mathrm{Al}$ alloy attributes the decrease in micro hardness [21].Consequently; the filler metal used in TIG welding is 5356 electrode which contains Magnesium, Manganese and chromium as principal alloying elements. These alloying elements may precipitate carbides which may contribute to the higher hardness levels [23].

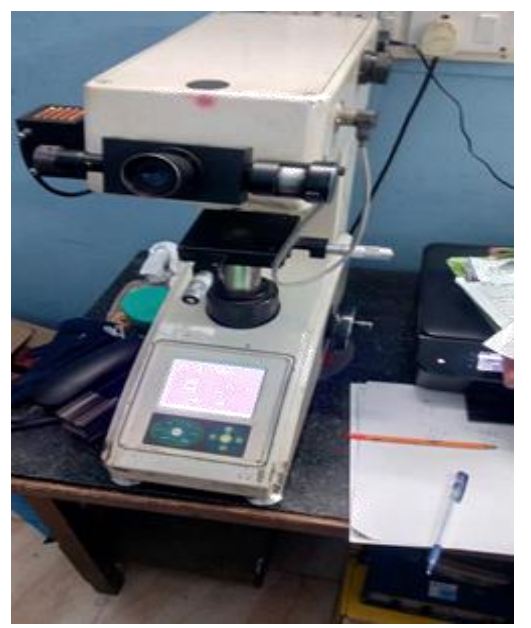

Fig.3. Microhardness testing setup

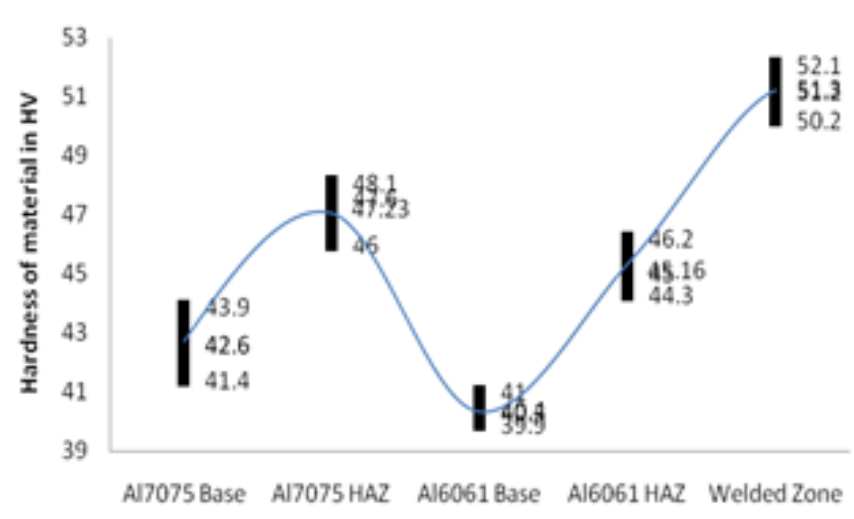

Specimen materials

Chart. 1. Comparison of different specimen materials vs. $\mathbf{H V}$

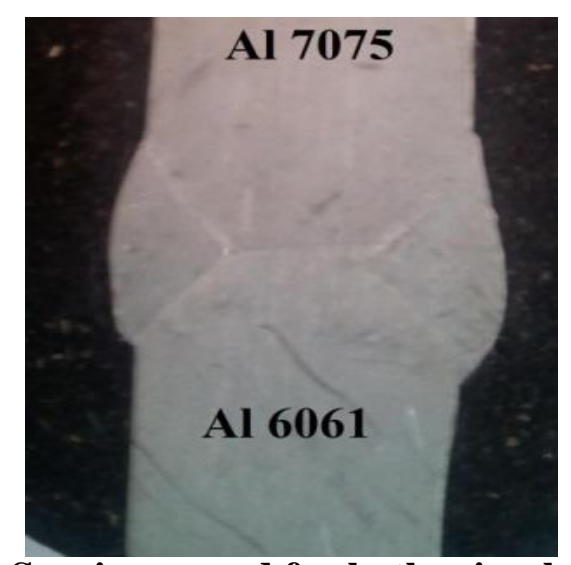

Fig.4. Specimen used for both microhardness and microstructure

The base material hardness of AA6061 alloy is reduced towards the stir zone to HV 68 in D65 joints and further decreased to HV 65 towards AA5086 alloy side [24]. Since the hardness in the base material is scattered between 50 to $53 \mathrm{HV}$. And the GMAW process the HAZ having maximum hardness and away from weld zone the hardness is gradually reducing. GTAW process welding center zone hardness varies from 69.8 to 59.9 gradually decreasing to base material hardness [24]. In Chart no. 1. It is clearly evident that there is a larger variance in the hardness values in the Al7075 and Al6061 dissimilar joint (weld zone) with the maximum hardness value of 51.3HV.

D. Microstructure analysis

The welded joint is composed of a fusion zone (FZ), a wide HAZ, and a BM area. Irregular distribution of coarse particles throughout the BM is observed clearly. An equiaxed dendritic network is formed in the FZ. Generally, the fine 
microstructure of the $\mathrm{FZ}$ is attributed to the high cooling rate associated with the TIG welding [8]. The 6061-T6 Al alloy has co-axial grains while, the 7075-T651 alloy has longitudinally oriented grain structure. The grain structure of the 7075 alloy was seen to be oriented in rolling direction of Aluminium sheet. Some second phase particles were revealed among the rolling microstructure. Fine equiaxed dendritic network grains were observed in weld metal at the fusion boundary. A dendritic structure was formed in weld fusion zone and caused alloying element segregation. HAZ is formed in different grain sizes and widths at 6061 and 7075 alloy portions of dissimilar RSW joints. The HAZ for 6061 alloy plate was narrower in comparison to the HAZ at the 7075 alloy plate, due to the different properties of the alloys. Hot cracking is normal in the alloys with wide solidification range, such as, $\mathrm{Al}-\mathrm{Mn}, \mathrm{Al}-\mathrm{Si}, \mathrm{Al}-$ $\mathrm{Cu}, \mathrm{Al}-\mathrm{Mg}$ alloys. Hot cracks usually occur above the solidus curve and in the solidification range [21]. Microstructure evolution in the base material is normally elongated grains due to rolling process. There is a coarsened dendritic grain structure in the WC zone. Grain size is quit variable in these areas, and is much longer than the original BM grains. The lamellar grains are the welding regions, BM region quite lamellar to coarsened grains are forms. The grain size is fine at welding region in FSW. The FSW welding region grains are compared to BM it is more or less similar. The fine grain size would affect increasing mechanical properties [24]. Due to the heat input the welding zone and HAZ is affected by the tensile properties. GMAW process the fracture occurred in the HAZ. The tensile properties would not affect the weld zone due to the high welding strength [24]. Microstructure of the parent metal has revealed spheroidal particles of $\mathrm{MgZn}$ (black precipitates) and light grey particles of $\mathrm{FeAl} 3$ present in the Aluminium soild solution. We can also see the grains elongated along one direction. Microstructure of the weld metal has revealed interdendritic eutectic with light grey particles of FeAl3 present in the 1 solid solution. The microstructure of the HAZ has revealed elongated grains with grain boundary eutectic and light grey particles of $\mathrm{Fe} 3 \mathrm{Al}$ present in the Aluminium solid solution [23]. Microstructure of all the joints was examined at different locations, but most of the tensile specimens failed in the weld metal region, and the optical micrographs taken at the weld metal region alone. The base metal contains coarse and elongated grains with uniformly distributed very fine precipitates. The fusion zone of GMAW and GTAW joints contain dendritic structure and this may be due to the fast heating of base metal and fast cooling of molten metal due to welding heat. The only difference between these two dendritic structures is the dendrite arm spacing. The spacing is marginally wider in GMAW joint and narrower in GTAW joint. However, the weld region of FSW joint contains very fine, equiaxed grains and this may be due to the dynamic recrystallization that occurred during FSW process [25]. The microstructure of base metal consists of very fine insoluble second phase precipitates dispersed in various locations. The base metal grains are elongated in the rolling direction. In the TMAZ region the bending of the grains is observed which is due to the plastic deformation resulting by the stirring action. From the micro structural study it has been observed that the larger is the shoulder diameter, the wider is the TMAZ due to increased contact area between the tool and the work piece. The microstructure shows poor weld metal consolidation is the stir region resulting into the lowest joint efficiency.

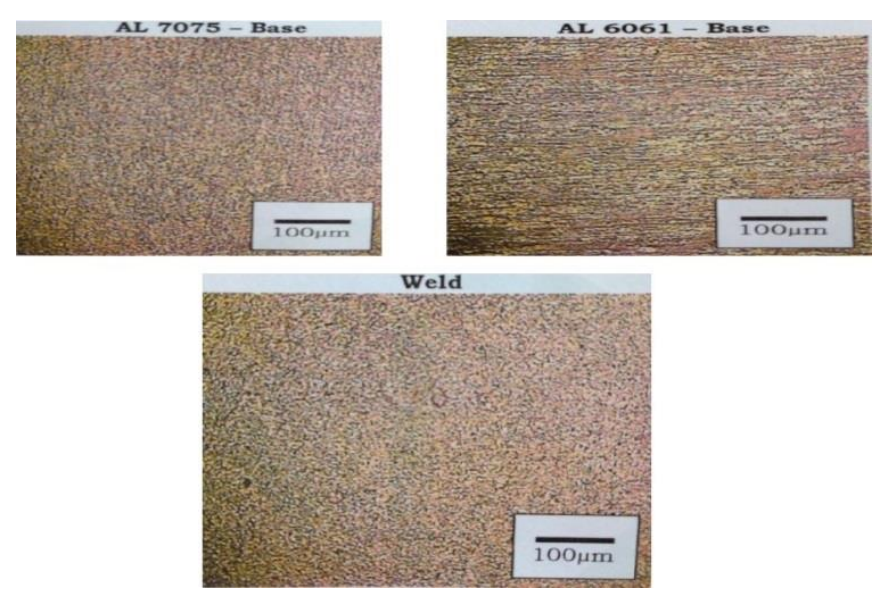

\section{Fig.5. Microstructure of Al7075, Al6061 and welded zone}

$\mathrm{Mg}$ alloys possess lower melting temperatures than $\mathrm{Al}$, and they are highly reactive at elevated temperatures. Al and $\mathrm{Mg}$ alloys also possess low solubility in each other. The grains in the microstructure of the PMZ of the A7075-T651 alloy recrystallized; thus, the grains increased in size. The grain boundary became shaggy compared 
with that of the parent alloy because of the effects of welding heat. The microstructure showed that the grains in the PMZ of the A70750-T651 alloy were equiaxed [7]. The second-phase undissolved particles, such as $\mathrm{A} 12 \mathrm{Cu} \mathrm{Fe}$ or $\mathrm{Al} 2 \mathrm{Cu} \mathrm{Fe} 4$, are identified in the base metal. The BM of AA6061T6 consists of elongated grains of the parent metal with fine precipitated particles of $\mathrm{Mg} 2 \mathrm{Si}$ eutectics, which are evenly present. The microstructure shows elongated grains of Aluminum solid solution with finely precipitated eutectics of the strengthening phases. The various precipitated eutectics are $\mathrm{Zn}-\mathrm{Al} 2, \mathrm{Mg} 2 \mathrm{Si}, \mathrm{MgAl} 2$, and $\mathrm{CuAl} 2$. In the thermo-mechanical heat affected zone AA7075-T6, the direction of flow patterns of grains was changed to the raw material flow due to severe plastic deformation. The elongated grains of the parent metal were changed perpendicularly, the presence eutectics were also observed and these particles were of considerable quantity having fine dispersive nature. The heat affected zone AA7075T6 shows elongated coarse grains with intermetallic particles which are agglomerated in an irregular pattern towards the flow. This might be due to the lower temperature difference when compared with interface and thermo mechanical zones. The microstructure shows Fig. 5. the interface zone which dynamically recrystalized, that there is sufficient plastic deformation and good bonding between these alloys which gave high brittle strength due to the fine uniformly distributed grains. All the dissolved eutectics of the alloy have re-appeared due to heat. The grain of the eutectic has fragmented and present as agglomeration with fine grains. This zone contains the eutectic particles of both Al7075 and Al6061. However the same was contributed as very fine particles, mostly AA7075-T6 diffused in AA6061T6, are observed [20].

\section{CONCLUSION}

The tensile properties of welded region is low where else, the energy absorbed by the specimen is about 16 joules, which possess high impact strength under TIG welding process. From the experiment the microhardness $(51.3 \mathrm{HV})$ appeared in welded zone is higher than parent materials, it attributes that due to low ductility properties. However, with high impact strength the Al7075 and Al6061 welded specimen the brittle strength has improved. The microstructure (HAZ) image shows, that there is sufficient plastic deformation and good bonding strength between the dissimilar alloys which give high brittle strength due to the fine uniformly distributed grains.

\section{References}

[1] Palani PK, Saju M, “Optimization of process parameters for TIG welding of Aluminium65032," International Journal of Engineering Research and Applications,Vol. 3, 2013, 230236.

[2] N Karunakaran, V Balasubramanian, "Effect of pulsed current on gas tungsten arc welded Aluminum alloy joints," Journals of Science Direct (SP), 21, 2010, 278-286.

[3] Yashwant Thakur, Khushmeet Kumar, Krishan Kumar, "Influences of TIG welding parameters on tensile and impact behaviour of Aluminium alloy joints: A Review," IOSR-JMCE, 2016, pp.54-58.

[4] K.S. Pujari and D.V. Patil, "Optimization of GTAW Process Parameters on Mechanical Properties of AA 7075-T6 Weldments," Springer Science \& Business Media Singapore, 2017, 187-195.

[5] Yan YB, Zhang ZW, Shen W, Wang JH, Zhang LK, Chin BA, "Microstructure and properties of magnesium AZ31B-Aluminum 7075 explosively welded composite plate," Mater Sci Eng A527(9): 2010, 2241-2245.

[6] X-d Q, L-m L, "Fusion welding of Fe-added lap joints between AZ31B magnesium alloy and 6061 Aluminum alloy by hybrid lasertungsten inert gas welding technique" Mater Des 33: 2012, 436-443.

[7] M. R. Islam, M. Ishak, L. H. Shah, S. R. A. Idris, C. Meriç, "Dissimilar welding of A7075T651 and AZ31B alloys by gas metal arc plug welding method," Int J Adv Manuf Technol, 2016.

[8] Dong Peng, JunShen, QinTang, Cui-pingWu, and Yan-bing Zhou, "Efects of aging treatment and heat input on the microstructures and mechanical properties of TIG-welded 6061-T6 alloy joints," International Journal of Minerals, Metallurgy, and Materials 2013, pp 259-265.

[9] R. Ahmad, M.A. Bakar, "Effect of a post-weld heat treatment on the mechanical and 
microstructure properties of AA6061 joints welded by the gas metal arc welding cold metal transfer method," Materials and Design. 32, 2011, 5120-5126.

[10] Gadewar.S, Swaminadhan.P and Harkare.M, "Experimental investigations of weld characteristics for a Single pass TIG welding with Stainless steel, Journal of Engineering and Technology," Vol.2, No.8, 2010, pp.3676-3686.

[11] Li Qing-Ming, Wang Xin-Hong, Zou Zeng-Da and $\mathrm{Wu}$ Jun, "Effect of Activating Flux on Arc Shape and Arc Voltage in Tungsten Inert Gas Welding," Science Direct, Vol 17, Issue 3, 2007, pp.486-490.

[12] R.Ahmad and M.A.Bakar, "Effect of postweld heat treatment on the mechanical and microstructure properties of AA6061 joints welded by the gas metal arc welding cold metal transfer method," Materials and Design, 32, 2011, pp.5120-5126.

[13] Rajesh.P.Verma and K.N.Pandey, "Investigation of Fatigue Life of 6061-T6 and 5083-O Aluminium Alloys Welded by Two Welding Processes- Manual Metal Arc Welding and Metal Inert Gas Welding," International Conference on Mechanical and Industrial Engineering (ICMIE), Dehradun, ISBN: 978-93-82208-20-4, 2012, pp.46-50.

[14] Sachin.L.S, Mayur.S, Pavan.K.M, Chandrashekar.A, and B.S. Ajaykumar, "Evaluation of Structural and Mechanical Properties of TIG Welded Aluminium Alloy AA-5083 Subjected to Post Cryogenic Treatment," Journal of Material Science and Mechanical Engineering (JMSME), 2015, pp. 82-86.

[15] S. C. Juang and Y. S. Tarng, "Process parameter selection for optimizing the weld pool geometry in the TIG welding of stainless steel," Journal of Material Process Technology, Vol. 122, No. 1, 2002, pp. 33-37.

[16] Balasubramanian $\mathrm{M}$ and Balasubramanain V, "Process Parameter Optimization of the Pulsed GTAW of Titanium Alloy," Journal of Material Science and Technology, Vol. 24, No. 3, 2008, pp. 423-426.

[17] Indira Rani M, R N Marpu, "Effect of Pulsed Current TIG Welding Parameters on Mechanical Properties of J-Joint Strength of
AA635" The International Journal of Engineering And Science (IJES), 2012, pp 1-5.

[18] Sanjeev Kumar, "Experimental Investigations on Pulsed TIG Welding of Aluminium Plate," International Journal of Advanced Engineering Technology, 2010, pp 200-211.

[19] Zhihua Chen, Jie Lu, Hongbo Liu, Xiangwei Liao, "Experimental investigation on the post-fire mechanical properties of structural Aluminum alloys 6061-T6 and 7075-T73," Thin-Walled Structures 106, 2016, 187-200.

[20] Ahmed Khalid Hussain, Abdul Lateef, M ohd Javed, Pramesh.T, "Influence of Welding Speed on Tensile Strength of We lded Joint in TIG Welding Process,"

International Journal of Applied Engineering R esearch, 2010, pp 518-527.

[21] Fatih Haya, "Effect of aging treatment on the microstructure and mechanical properties the similar and dissimilar 6061-T6/7075-T651 RSW joints," Materials Science \& Engineering A 556, 2012, 834-843.

[22] M. Temmar, M. Hadji, T. Sahraoui, Mater, "Effect of post-weld aging treatment on mechanical properties of Tungsten Inert Gas welded low thickness 7075 Aluminium alloy joints,"Materials and Design 32, 2011, 35323536.

[23] Sivashanmugam M, Manoharan N , Ananthapadmanaban D, Ravi Kumar S, "Investigation of "Microstructure And Mechanical Properties of GTAW And GMAW Joints of AA7075 Aluminum Alloy," International Journal on Design and Manufacturing Technologies, 2009, pp 56-62.

[24] A. K. Lakshminarayanan \& V. Balasubramanian \& K. Elangovan, "Effect of welding processes on tensile properties of AA6061 Aluminium alloy joints," Int J Adv Manuf Technol, 2009, 40:286-296.

[25] P.Z. Zhao, T. Tsuchida, "Effect of fabrication conditions and $\mathrm{Cr}, \mathrm{Zr}$ contents on the grain structure of 7075 and 6061 Aluminum alloys," Materials Science and Engineering A 499, 2009, 78-82. 